\title{
Improved estimation of flood parameters by combining space based SAR data with very high resolution digital elevation data
}

\author{
H. Zwenzner and S. Voigt \\ German Remote Sensing Data Center, German Aerospace Center, Oberpfaffenhofen, Germany \\ Received: 12 September 2008 - Published in Hydrol. Earth Syst. Sci. Discuss.: 29 October 2008 \\ Revised: 20 April 2009 - Accepted: 4 May 2009 - Published: 11 May 2009
}

\begin{abstract}
Severe flood events turned out to be the most devastating catastrophes for Europe's population, economy and environment during the past decades. The total loss caused by the August 2002 flood is estimated to be 10 billion Euros for Germany alone. Due to their capability to present a synoptic view of the spatial extent of floods, remote sensing technology, and especially synthetic aperture radar (SAR) systems, have been successfully applied for flood mapping and monitoring applications. However, the quality and accuracy of the flood masks and derived flood parameters always depends on the scale and the geometric precision of the original data as well as on the classification accuracy of the derived data products. The incorporation of auxiliary information such as elevation data can help to improve the plausibility and reliability of the derived flood masks as well as higher level products. This paper presents methods to improve the matching of flood masks with very high resolution digital elevation models as derived from LiDAR measurements for example. In the following, a cross section approach is presented that allows the dynamic fitting of the position of flood mask profiles according to the underlying terrain information from the DEM. This approach is tested in two study areas, using different input data sets. The first test area is part of the Elbe River (Germany) where flood masks derived from Radarsat-1 and IKONOS during the 2002 flood are used in combination with a LiDAR DEM of $1 \mathrm{~m}$ spatial resolution. The other test data set is located on the River Severn (UK) and flood masks derived from the TerraSAR-X satellite and aerial photos acquired during the 2007 flood are used in combination with a LiDAR DEM of $2 \mathrm{~m}$ pixel spacing. By means of these two examples the performance of the matching technique and the
\end{abstract}

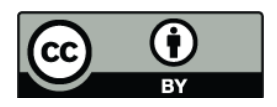

Correspondence to: $\mathrm{H}$. Zwenzner (hendrik.zwenzner@dlr.de) scaling effects are analysed and discussed. Furthermore, the systematic flood mapping capability of the different imaging systems are examined. It could be shown that the combination of high resolution SAR data and LiDAR DEM allows the derivation of higher level flood parameters such as flood depth estimates, as presented for the Severn area. Finally, the potential and the constraints of the approach are evaluated and discussed.

\section{Introduction}

Mapping of large scale flood events is not only of major concern for disaster response teams and flood management officials but also poses a key task to hydrologists and the industry in order to generate reference data and calibration information for dynamic flood models, damage estimates, flood plain mapping tasks and further applications. This applies for gauged basins, where gauges may fail or where flooded areas cannot be characterised sufficiently by the gauge data alone, and it applies even more for ungauged basins, where often only little information on the flood dynamics and basin response to extreme events is available. During the past decades airborne and space-borne remote sensing platforms have been frequently used to map and monitor flood extent in all kinds of basins (Horritt et al., 2003; Sanyal and Lu, 2004; Wang, 2004; Schneiderhan et al., 2007). However, in many cases flood extent alone is not sufficient to characterise a given flood situation adequately. Often parameters like inundation depth or duration of a specific flood situation are required, e. g. as input for damage models (Thieken et al., 2005). As different remote sensing sensors have different ground resolution and varying flood/water detection potential, it is important to be aware of such limitations

Published by Copernicus Publications on behalf of the European Geosciences Union. 
when processing the respective flood masks in GIS operations or when generating flood maps. This is the case when flood masks are combined with digital elevation data to derive spatially distributed estimates of inundation depths or to exactly locate the land-water boundary in a digital terrain model (Sanders, 2007; Mason et al., 2007; Ling et al., 2008). In such cases even small geometric inaccuracies during the geocoding process or slight classification errors (local or general in character) can significantly reduce the quality of higher level products such as maps of inundation depths. Another approach for the estimation of uncertainty of observed inundation extent is the implementation of a fuzzy evaluation methodology (Pappenberger et al., 2007).

In order to enhance the geometric and thematic reliability of flood masks derived by remote sensing techniques, we here present methods to improve the matching of flood masks with very high resolution digital elevation models as derived from LiDAR measurements (Fowler, 2002). By applying these matching techniques, the hydrological plausibility and reliability of flood masks is improved, so that further processing in hydrological or hydraulic models can be performed with sufficient accuracy. This is of particular relevance whenever applying remote sensing techniques to operational flood monitoring or for rapid mapping purposes, i.e. when the processing and verification of the results have to be achieved under time pressure. Only a few authors have presented techniques to establish such links of remotely sensed flood masks with high resolution digital elevation data sets. Schumann et al. (2006) present a georeferencing adjustment method which shifts the SAR image until an acceptable agreement between left and right flood extent water level is found. Matgen et al. (2007) tested and compared methods for flood depth interpolation based on flood masks derived from SAR imagery. Bates et al. (2006) used a 2-D hydraulic model approach to cross-compare the results with SAR derived flood extent maps, while Meinel et al. (2003) presented concepts for computing water levels using elevation readings from intersecting IKONOS flood masks with LiDAR DEMs and terrestrial land/water line observations. Schumann et al. (2007) used different regression models to fit the left and right bank elevation readings from SAR based water mask/DEM intersections. All authors described the difficulty of precisely combining water masks and DEMs, as geometric errors and thematic classification errors in the remote sensing data remain high. The methods presented in this paper seek to reduce such residual errors through local matching operations.

\section{Methodological approach}

The technique presented here is based on the concept of locally fitting a carefully processed flood mask into high resolution digital elevation data sets. Whereas Schumann et al. (2006) for example presented a method which shifts the entire flood mask in order to achieve coherence with the underlying elevation data, the proposed method is based on a sequence of densely spaced cross sections which are shifted and adjusted individually. The assumption is that small-scale geometric or thematic classification errors can be compensated by the fitting process and the hydraulic accuracy can be improved through these fitting operations. However, the matching process can only be carried out within certain limits, as the approach is neither meant to inter- or extrapolate flood masks nor to substitute accurate hydraulic approaches. Two major assumptions for the fitting process and the derivation of flood depth are, that each cross section has a horizontal water level and that only minor thematic errors (in the order of some pixels) exist in the satellite-derived flood profiles. The character and accuracy of the digital elevation data is of key relevance to this approach, as remaining artefacts like vegetation, removable objects or interpolation errors in the DEM have an influence on the matching result (Fowler, 2002).

Figure 1 illustrates the sequence of the most important processing steps of the proposed method. Initially, the terrain profiles are generated perpendicularly to the centreline of the river. Ideally, this line should be the centreline of the area of the flood water body given by the flood mask, rather than the centreline of the normal water body. Especially for large flood situations, when the water flow takes a different path than normal river flow, the centreline should represent the effective flood situation. In order to avoid too much overlap between the cross sections, the sinuosity of centreline should be minimised. The distance between cross sections as well as the sampling distance within profiles depends on the geometric resolution of the remote sensing data from which the water mask was derived.

The cross sections are set up as profiles of the river basin topography which turns into bathymetry once the river is flooded. Once the respective river section is characterised by these profiles they can be used for intersection with the flood mask. According to Fig. 1 the next processing step is depicted in the upper yellow box named "profile shifting, water level derivation". This processing step is carried out for each single cross-section profile. For each profile segment labelled as "flooded" the mean elevation is derived from the DEM and a plausibility check is carried out. All segments which exceed a threshold of $2 \mathrm{~m}$ above the mean elevation of the flood profile are excluded, as they are obviously misclassified due to shadow or layover effects in the SAR data. For the remaining cross section profile the elevation reading of the left border is compared to the elevation of the right border. Assuming a planar water level orthogonally to the flow direction the flood profile with a fixed length is shifted along the cross section until the optimal position is found and the elevation of the left and right border are leveled out. Theoretically, this step provides the possibility to compensate for a systematic geometric displacement of the remote sensing data on the basis of the elevation model. However, 
this shift can only be applied within defined limits and we propose a threshold of a maximal shift in the order of 5-10 pixels depending on the general processing and classification accuracy of the flood mask. A larger shift would bias the determination of the water level. At this point it should be noted that the SAR image should be geo-referenced as accurately as possible beforehand, in order to minimise the geometric error. Finally, the elevation of the flood water level is calculated from the elevation of the left and right border for each individual flood profile.

The next processing step is the generation of the longitudinal flood level profile, illustrated by the red-framed box in Fig. 1, which consists of the sequence of the water level estimates of each individual cross section along the river flow line. The longitudinal profile is a key instrument of the proposed methodology since the derived water level estimates of the individual profiles can be visualised and compared against water gauge data and other reference data if available. This information can be used as an indicator of how well the water levels have been derived and where problems such as classification errors occurred. During this step it has to be evaluated if the quality of the derived water level estimates allows the reliable mapping of inundation depth or not. Examples are given in chapter 3 and 4 . On the basis of the longitudinal profile the water level estimates can be corrected in such a way that obvious errors due to misclassifications are reduced. Hence, a moving average is applied to the longitudinal sequence of the water level estimates in order to obtain a naturally smooth water surface which serves as reference water level for the flood depth delineation. Theoretically, this step allows for the compensation of small-scale thematic and/or geometric errors in such a way that variations in the water level estimates of subsequent cross sections are averaged and outliers are removed. The limitation of this approach is that classification errors that range over more than a few cross sections can not be compensated. This occurs for example when the flood extent of a relatively large area of the river section is underestimated due to flooded vegetation. In this case the water level would be underestimated as well, and the respective flood profiles would have to be excluded or the errors be reduced by further pre-processing. This highlights the importance of the visual interpretation and crosschecking of the longitudinal profile.

In the next processing step named "profile adjustment" in Fig. 1 the modified water level estimates are used to adjust the horizontal extent of the cross section flood profiles. This means that each individual flood profile is trimmed or extended on the basis of its reference water level from the longitudinal profile and is thus fitted to the flood plain topography.

The last processing step illustrated in Fig. 1 is the derivation and mapping of inundation depth. From the xyzcoordinates of the left and right border of the adjusted flood profiles a Triangulated Irregular Network (TIN) is created. A continuous flood water surface which represents the rec-

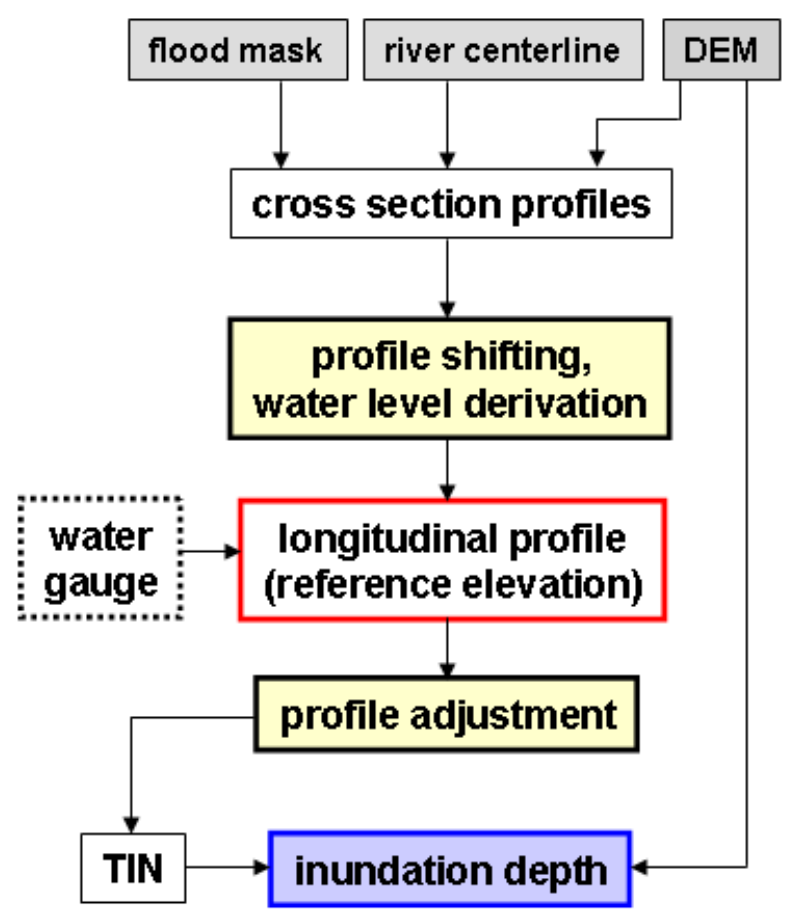

Fig. 1. Flowchart showing the interconnection of the major processing steps for the mapping of inundation depth. The grey boxes depict the input datasets for the river parameterization via crosssections, the yellow-colored boxes illustrate the processing steps for each single cross-section and the red-framed box describes the integration process of all single cross-section profiles within the longitudinal profile. If available, water gauge data should be incorporated. The terrain adjusted profile heights are transformed into a raster file via a TIN and inundation depth can be derived by subtracting the terrain elevation from the elevation of the water surface.

tified water levels from the longitudinal profile is generated via TIN interpolation. The resulting raster layer of inundation depth is then computed by subtracting the DEM from the rasterised TIN.

The profile matching algorithm is implemented in IDL (interactive data language). Each profile is stored in a database and all intersections, cross-checking and matching operations can be computed independently. Hence, even large data sets can be handled quite easily and the precomputed profile database can be used for a wide range of flood situations.

\section{Case study on River Elbe, Germany}

\subsection{Study area and flood situation}

The extreme flood event in August 2002 affected a number of rivers in Central Europe and especially the Elbe. Due to all-time high summer rainfall amounts and intensities in the headwaters and tributaries of the Elbe River, the water gauge at the city centre of Dresden measured a record water level 


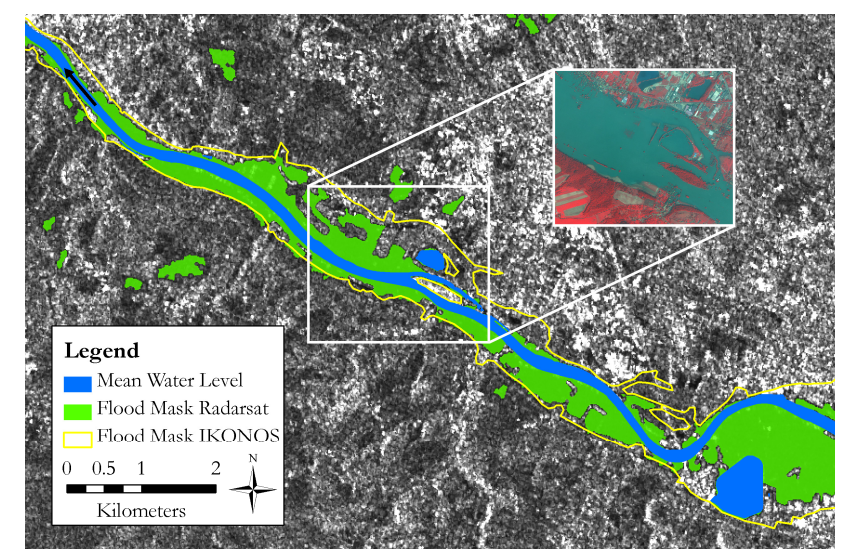

Fig. 2. Radarsat-1 image showing the flood situation of the Elbe River 15 km north-west of Dresden (Germany) on 18 August 2002, one day after the flood peak. For comparison a small subset of an IKONOS false colour image is presented which was acquired three hours after the Radarsat-1 scene.

of $9.4 \mathrm{~m}$ on 17 August 2002. This flood level exceeded the previously recorded all-time flood peak of the year 1845 by $63 \mathrm{~cm}$.

Figure 2 gives an overview of the study area which comprises a section of the middle course of the Elbe River of about $15 \mathrm{~km}$ length. The heavily flooded city centre of Dresden is located about $20 \mathrm{~km}$ upstream, southeast of the study area. The floodplain geomorphology exhibits pronounced terrain with some steep slopes adjacent to the water course. The topographic gradient of $7 \mathrm{~m}$ and the resulting average longitudinal slope of $0.0005 \mathrm{~m} / \mathrm{m}$ for this river section provokes a straight river flow.

\subsection{Data sets and pre-processing}

A Radarsat-1 scene showing the flood situation of the Elbe River on 18 August 2002, one day after the flood peak, was used for this study. The incidence angle was $41^{\circ}$ and the polarisation of the C-Band Radarsat-1 sensor was HH. First of all, the raw satellite data were processed and geocoded using one ground control point (GCP) to improve the positional accuracy. The accuracy assessment based on 8 independent GCPs gave a total RMSE of $16.59 \mathrm{~m}$. The pixel spacing of the processed image was $12.5 \mathrm{~m}$. A standard edge-preserving adaptive Lee-Sigma filter with a window size of $7 \times 7$ pixels was then applied on the SAR data in order to reduce speckle and to support homogeneous water classification (Sheng and Xia, 1996). A binary flood mask was derived using a pixelbased threshold classification approach (Brivio et al., 2002; Bonn and Dixon, 2005). The assumption of the threshold classification approach is that all pixels with backscatter intensities below a certain threshold are classified as "flooded" whereas pixels with higher backscatter values are classified as "non-flooded". The resulting classified flood extents were

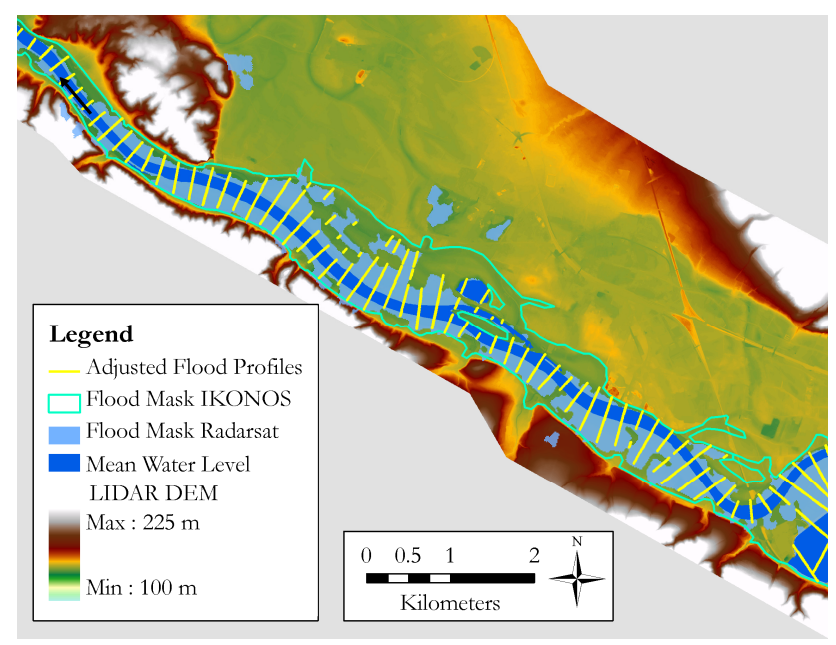

Fig. 3. Elevation map of the Elbe River north-west of Dresden with the original flood mask derived from Radarsat-1 (light blue). The cross section flood profiles with a spacing of $100 \mathrm{~m}$ were horizontally shifted according to the underlying terrain data and are drawn in yellow. For comparison the flood mask derived from IKONOS is encircled by the lime-green line.

visually compared against official municipality flood maps derived from aerial survey, ground truth information and citizen interviews. The errors were evaluated qualitatively by visual interpretation and fine tuning of the threshold was done at a number of selected points for which the water boundary could be reliably identified from the reference data. As a final step of the classification small islands and lakes were removed.

A LiDAR DEM of the Elbe flood plain with $1 \mathrm{~m}$ horizontal resolution and a vertical accuracy of $0.1 \mathrm{~m}$ was available for the study area. For validation and cross-comparison an optical IKONOS satellite image with four channels and $1 \mathrm{~m}$ resolution, acquired three hours after the Radarsat-1 scene, was used. The IKONOS scene was orthorectified and visually interpreted. Because of its high spatial resolution and the good perceptibility of the flooded area, especially in the near infrared channel, a detailed flood mask could be digitised. This flood mask showed good agreement with the official high resolution flood maps and is thus considered to reliably reflect the real flood situation.

\subsection{Case specific analysis}

As indicated in Fig. 2, the flood mask derived from Radarsat1 data shows large differences in flood extent when compared to the flood mask inferred from IKONOS imagery. According to the geometric resolution of the Radarsat-1 data, cross section flood profiles were generated at intervals of $100 \mathrm{~m}$ along the centreline of the water course as shown in Fig. 3. The sampling distance along the profiles was $10 \mathrm{~m}$. Figure 2 reveals that the Radarsat- 1 flood mask partially includes 


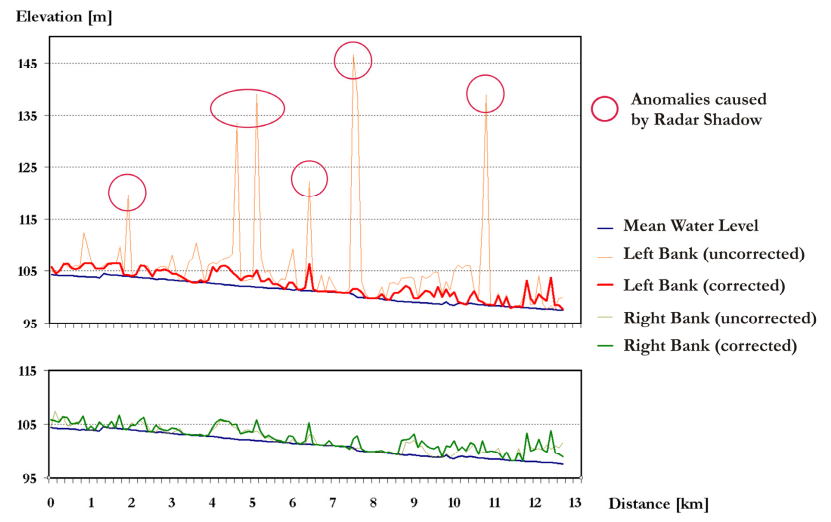

Fig. 4. Longitudinal profile showing the elevation of the left and right river bank at each individual Radarsat-1 profile before and after the rectification. Large anomalies can be recognised in the uncorrected elevation readings of the left river bank caused by misclassification of water due to radar shadow. After the horizontal adjustment (shifting) of the profile, elevation readings of the left and right river bank correspond to each other.

areas on the hill slopes of the left river bank which were misclassified because of low backscatter intensities due to geometric effects such as radar shadow or stretching of the backside of the mountain. Obviously misclassified profile segments and segments not connected to the main flood surface were excluded from further processing. By applying the profile shifting methodology described in Sect. 2, all valid profile segments were shifted horizontally and adjusted to the flood plain topography. Figure 4 shows a comparison of the elevation of the left and right boundary of the flood profiles in flow direction, before and after the shifting was performed. Large outliers on the left bank are visible in the uncorrected flood profiles.

The same method and cross section profiles were applied on the flood mask derived from IKONOS imagery. Figure 5 presents a comparison of the water level readings derived from Radarsat-1 and IKONOS for each individual profile along the river reach.

\subsection{Results}

By applying the profile shifting method large outliers in the elevation of the left river bank could be eliminated (see Fig. 4) and the flood profiles from Radarsat-1 data thus appear more plausible with respect to their position in the terrain. Figure 3 illustrates that all shifted flood profiles lie within the IKONOS flood mask. However, the results are rather disappointing with respect to the derived water levels depicted by the longitudinal profiles in Figs. 4 and 5 . The terrain-adjusted flood profiles from Radarsat- 1 indicate a large underestimation of the flood water levels when compared to water level estimates from IKONOS (see Fig. 5). Although also the water levels from IKONOS show a sig-

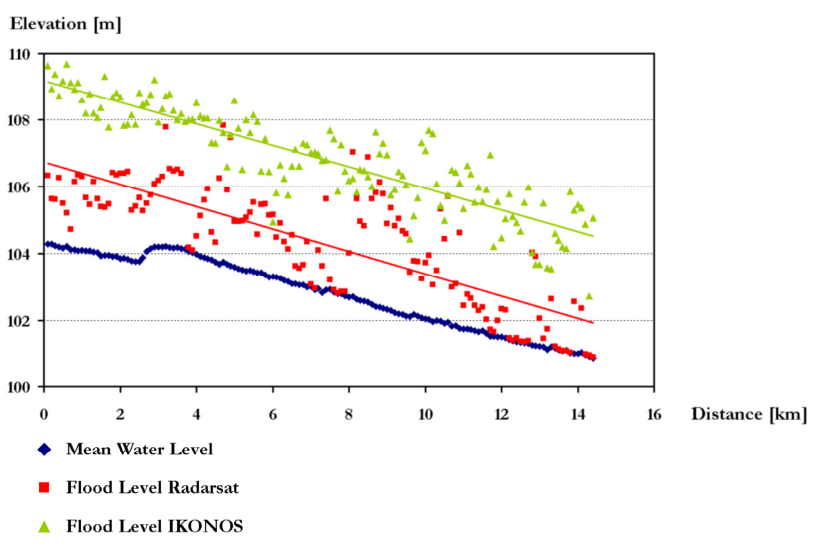

Fig. 5. Longitudinal profile of the Elbe River reach north-west of Dresden showing the water level estimates for each individual cross-section profile for Radarsat-1 (red) and IKONOS (green) in comparison to the pre-flood average water level (blue).

nificant scattering, the flood water levels derived from the Radarsat-1 profiles are much more variable. A number of flood profiles feature a water level similar to the pre-flood average water level as it is represented by the LiDAR elevation data. This is shown by the red data points which are located on the blue line in Fig. 5. Since flood extent and water level are closely correlated, it follows that the flood extent detected by Radarsat- 1 at these cross sections is largely underestimated and the profiles are too short. Thematic classification errors caused by high backscatter intensities from flooded vegetation and too much distortion from the proximity of the urban areas can be regarded as the main reasons for this. Also the pixel size of $12.5 \mathrm{~m}$ has a negative influence on the accuracy of the flood mask when compared to a high resolution DEM of $1 \mathrm{~m}$ pixel spacing.

A general underestimation of about $2 \mathrm{~m}$ compared to IKONOS such as it is shown by the regression lines in Fig. 5 leads to the conclusion that flood masks from traditionally medium resolution SAR sensors such as Radarsat-1 are not appropriate for such detailed analyses. The boundary conditions for the derivation of reliable flood water levels are not fulfilled and thus the following processing steps towards the generation of inundation depth are dismissed. This example shows that there is a need of much more appropriate radiometric as well as higher spatial resolutions of SAR images such as it is provided by TerraSAR-X.

\section{Application for high resolution SAR data at River Severn, UK}

\subsection{Study area and flood situation}

The severe flood situation on the River Severn occurred during the summer season and was induced by heavy and enduring rainfall over the Gloucestershire Region in Southeast 
Mythe Bridge water gauge (Tewkesbury, UK)

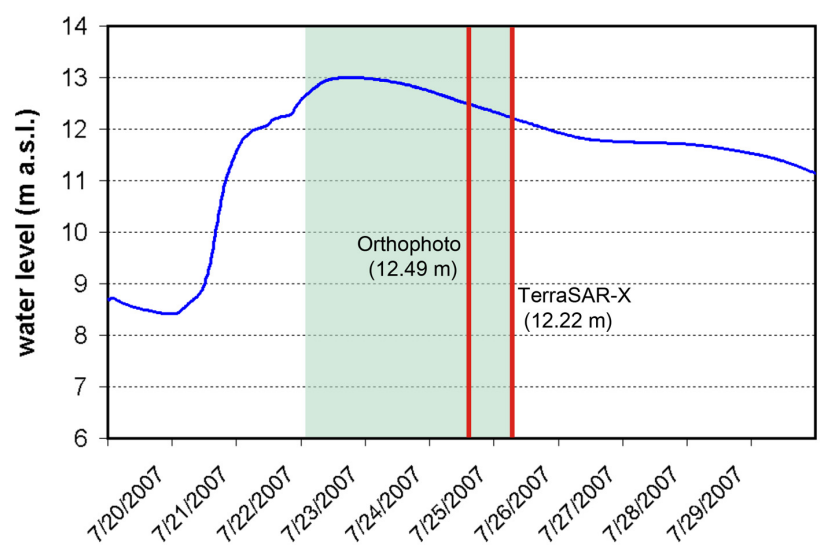

Fig. 6. Hydrograph of the Mythe Bridge water gauge at Tewkesbury, UK, showing the flood situation over 10 days from 20 July to 30 July 2007. The red bars depict the time of the data acquisitions of Orthophotos and TerraSAR-X and the respective water levels are given in brackets. During the $15 \mathrm{~h}$ time between the two acquisitions the water level decreased by $27 \mathrm{~cm}$. The green box depicts the period in which the accuracy of the water gauge data is limited by $+/-30 \mathrm{~mm}$ due to partial failure of the gauge and interpolation of missing values (data source: Environment Agency of England and Wales).

England. The record flood level at Tewkesbury measured $5.43 \mathrm{~m}$ on 22 July 2007 which was $13 \mathrm{~cm}$ above the previous record from the year 1947. A number of water gauges in the area did not operate regularly in terms of a continuous flood monitoring. Figure 6 shows the hydrograph of the River Severn at the water gauge at Mythe Bridge, Tewkesbury, which illustrates how the flood situation evolved. The flood situation was stable over several days. In the beginning it was induced by surface water from heavy local precipitation that could not drain away quickly and later it was characterised by inflow originating from upstream rainfall.

The study area presented in Fig. 7 comprises a section of the River Severn of about $8 \mathrm{~km}$ length including the confluence of the River Avon coming from northeast. The heavily flooded city of Tewkesbury is located east of the confluence and can be seen in the TerraSAR-X image as bright areas with high backscatter intensities (see Fig. 7). The Mythe Bridge water gauge is located $0.5 \mathrm{~km}$ north of the confluence of the two rivers. The study area is part of the lower course of the River Severn, and opposed to the Elbe River, the terrain is relatively flat with a very gentle gradient in flow direction which hampers flood water to drain away quickly.

\subsection{Data sets and Pre-processing}

This case study is based on a TerraSAR-X StripMap scene with $3 \mathrm{~m}$ pixel spacing showing the flood situation on 25 July 2007. The incidence angle was $24^{\circ}$ and $\mathrm{HH}$ polar-

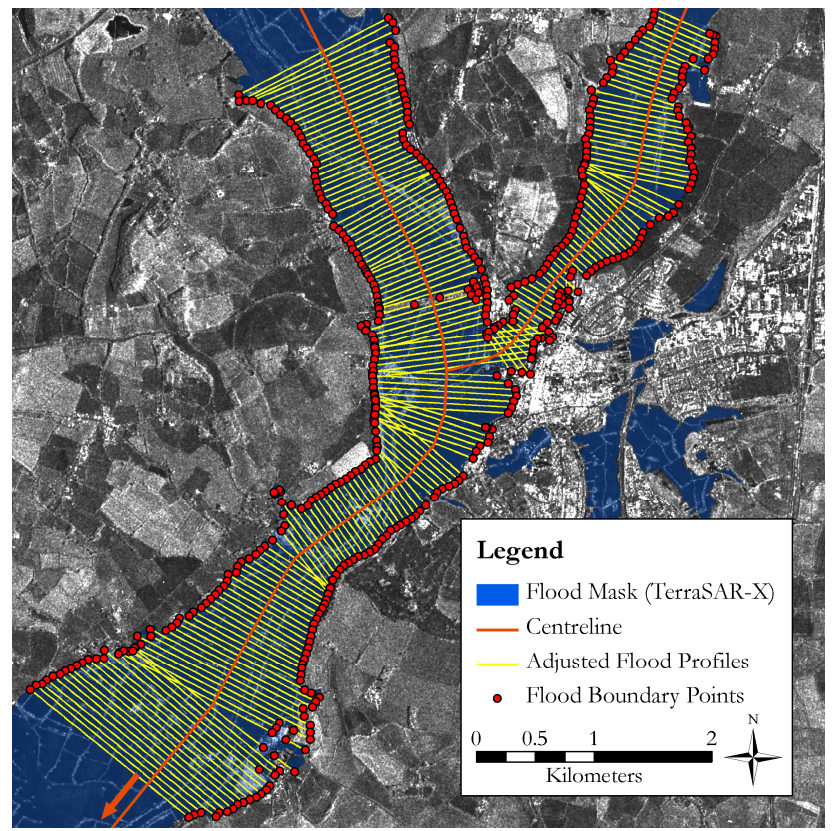

Fig. 7. TerraSAR-X image from 25 July 2007 showing the large flood event of the River Severn at Tewkesbury (UK). Cross section profiles with a distance of $50 \mathrm{~m}$ were created perpendicular to the flood centreline and were horizontally shifted according to the underlying high resolution elevation model. From the left and right boundary points the elevation of the water level could then be derived for each profile.

isation was chosen. The TerraSAR-X image was delivered in the standard high precision Enhanced Ellipsoid Corrected (EEC) format. The "rapid" orbit type (GPS orbit determination) was chosen which is advantageous for disaster response operations because of fast processing and data access. The pixel localisation accuracy of this orbit type is $2 \mathrm{~m}$, in flat areas it is even more precise. In order to reduce speckle and obtain homogeneous water classifications as well as to remove small islands in the data, an adaptive Lee-Sigma filter with a window size of $31 \times 31$ pixels was applied to the image. In contrast to the Elbe case study and the Radarsat1 pre-processing, a multiresolution segmentation was conducted on the high resolution TerraSAR-X data (Blaschke et al., 2000; Baatz and Schäpe, 2000).

Afterwards, a semi-automatic threshold classification approach was applied to the dataset. Small gaps were filled and adjoining ambiguous segments were added to reliably classified flooded segments by using neighbourhood functions. Finally, a binary flood mask with $3 \mathrm{~m}$ resolution was derived.

A LiDAR-DEM with a horizontal resolution of $2 \mathrm{~m}$ and a vertical accuracy of $0.1 \mathrm{~m}$ was used for this study. For validation and cross checking purposes, orthorectified aerial photographs acquired $15 \mathrm{~h}$ prior to the TerraSAR-X overpass could be obtained. Similarly to the IKONOS satellite imagery, the aerial photos were visually interpreted and a flood mask was derived by manual digitisation. 


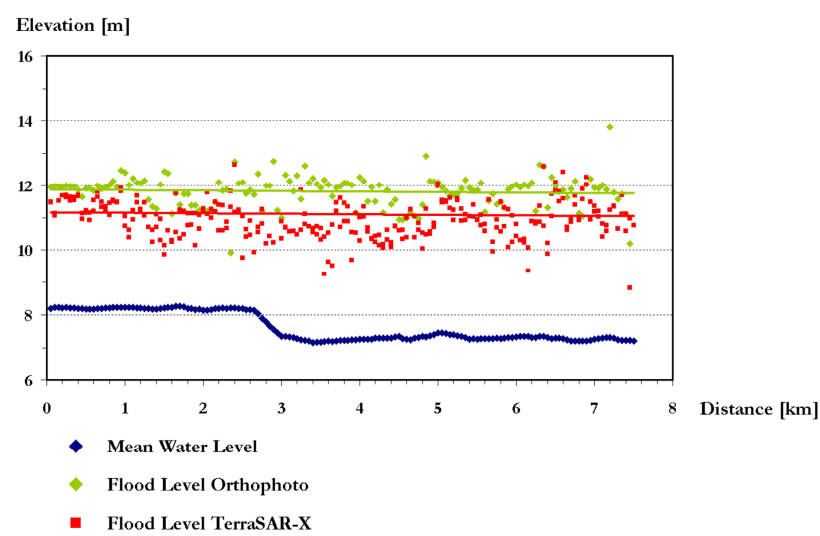

Fig. 8. Longitudinal profile of the Severn reach (exclusive of the River Avon) showing the elevation of the water level for each individual cross-section profile derived from TerraSARX (red) and from an Aerial Photography survey (green) one day prior to the satellite overpass in comparison to the pre-flood average water level (blue).

\subsection{Case specific analysis}

Corresponding to the higher resolution of the TerraSAR-X flood mask, cross section flood profiles were generated at intervals of $50 \mathrm{~m}$ between profiles and a sampling distance of $5 \mathrm{~m}$ along the profiles. As illustrated in Fig. 7, the cross section profiles were arranged orthogonally to the centreline of the flooded Severn and Avon. The centreline was manually digitised from the satellite imagery. The flooded areas in the city of Tewkesbury which were not connected to the main water body were excluded from this study. It turned out that these areas could not be sufficiently represented by the profile method based on the centreline of the main river.

The profile shifting method described in chapter 2 was applied to the flood profiles derived from the TerraSAR-X flood mask. A maximum horizontal shift of 5 pixels was allowed to achieve a horizontal water level. Subsequently, the water level of each individual cross section was derived from the elevation of the left and right border of the adjusted flood profiles. The same method was then conducted for the flood mask derived from the optical reference imagery. A comparison of the water level altitude of both data sets and each cross section is displayed in Fig. 8.

In contrast to the Elbe case study, the entire processing chain presented in chapter 2 was applied to the flood profiles derived from TerraSAR-X. Figure 9 presents the sequence of the water level elevation of each flood profile in flow direction, showing a total vertical variation of about $2.7 \mathrm{~m}$. The derived water level estimates were smoothed by applying a moving average filter over 31 cross sections. The smoothed water levels shown in Fig. 9 represent the longitudinal water surface of the river reach and serve as reference elevation for the flood depth computation. By applying the profile adjustment processing step, each individual flood pro-

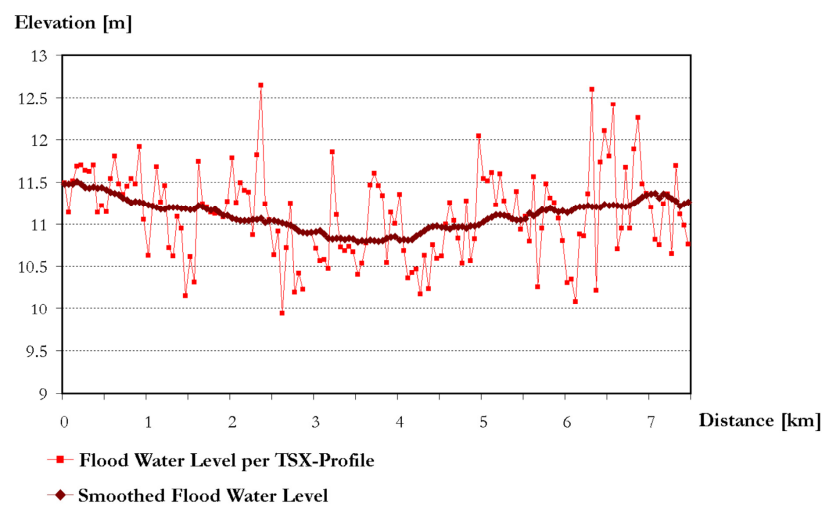

Fig. 9. Longitudinal Profile of the Severn reach (exclusive of the River Avon) showing the water level of the individual flood profiles derived from the TerraSAR-X flood mask. The water level estimates were smoothed by a moving average in order to diminish classification errors and possible inaccuracies in the elevation model. The smoothed line serves as reference flood level for the flood depth delineation.

file was trimmed or extended according to its respective reference elevation from the longitudinal profile. This means that all flood profiles were fitted to the local flood plain terrain. The coordinates of the resulting left and right border of the matched flood profiles were then used together with the reference elevation to create a water surface TIN. A continuous flood surface elevation was derived through TINinterpolation and was exported to a raster file. In order to obtain inundation depth, the DEM was subtracted from the rasterised water surface elevation. The result is illustrated in Fig. 10.

\subsection{Results}

Figure 8 indicates that the general flood situation is well represented by the TerraSAR-X flood profiles. The regression lines in Fig. 8 show that the water level estimates from TerraSAR-X data are on average about $80 \mathrm{~cm}$ lower than the water level estimates derived from aerial photography acquired $15 \mathrm{~h}$ earlier. At the Mythe Bridge water gauge (at $2.3 \mathrm{~km}$ on the longitudinal profile) the difference was actually $62 \mathrm{~cm}$. Due to the decreasing water level during the $15 \mathrm{~h}$ period between the acquisitions of TerraSAR-X and the aerial photos (see Fig. 6), $27 \mathrm{~cm}$ have to be subtracted, leaving a delta of $35 \mathrm{~cm}$ at Mythe Bridge. This means, that the TerraSAR-X water levels are underestimated by approximately $35 \mathrm{~cm}$ compared to water levels derived from orthophotos. The comparison of the water level estimates derived from TerraSAR-X and aerial photos with water gauge data is summarised in Table 1.

The systematic underestimation of $35 \mathrm{~cm}$ (up to $50 \mathrm{~cm}$ in urban areas) can be primarily attributed to the difference in spatial resolution, which is $3 \mathrm{~m}$ for TerraSAR-X and $0.2 \mathrm{~m}$ 
Table 1. Comparison of water gauge data and water level estimates derived from Terra-SAR-X and aerial photography at the time of the two data acquisitions at Mythe Bridge, Tewkesbury, UK.

\begin{tabular}{lccl}
\hline Acquisition Time & $\begin{array}{c}\text { Aerial Photography } \\
\text { 24/07/2007; } 1: 30 \text { p.m. }\end{array}$ & $\begin{array}{c}\text { TerraSAR-X } \\
\text { 25/07/2007; 6:30 a.m. }\end{array}$ & \\
\hline Water Gauge measurement & $12.49 \mathrm{~m}$ & $12.22 \mathrm{~m}$ & $\Delta 0.27 \mathrm{~m}$ \\
Remote Sensing estimate & $11.67 \mathrm{~m}$ & $11.05 \mathrm{~m}$ & $\Delta 0.62 \mathrm{~m}$ \\
& & & $\Delta 0.35 \mathrm{~m}$ \\
\hline
\end{tabular}

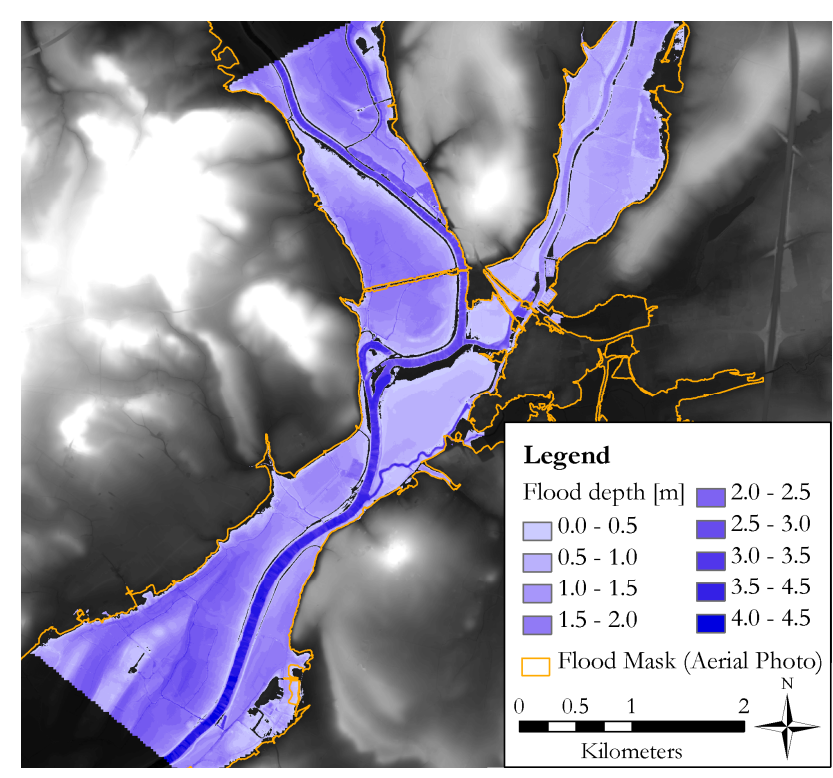

Fig. 10. Flood depth map of the River Severn near Tewkesbury derived from the rectified flood profiles of TerraSAR-X and a high resolution LiDAR elevation model. For comparison the flood extent derived from an aerial photography survey is shown by the yellow line. The urban area east of the river confluence was excluded from this study since the profile method was only applied along the river course.

for the orthophotos. The variability within the TerraSAR-X water level estimates illustrated in Fig. 9 is mainly caused by small scale geometric and classification errors due to higher backscatter from flooded vegetation, urban structures or a rough water surface. Figure 9 also shows the result of the averaging process of the flood water levels along the longitudinal profile in which local discontinuities in the elevation of the flood surface could be minimised.

However, the hydraulic situation shown in Fig. 9 is not as it would be usually expected. Although the reach length of $7 \mathrm{~km}$ in our study is very short and the topographic gradient in this area is too low in order to represent the natural downward trend of the river, a noticeable depression of the water level can be seen in the mid-section of the longi- tudinal profile. Classification problems around the city of Tewkesbury are most likely responsible for an underestimation of the flood extent and the resulting irregularities shown in Fig. 9. These classification errors in the TerraSAR-X derived flood mask were too large in scale to be compensated by the method applied.

As shown in Fig. 10, the created flood surface area from flood depth delineation corresponds well to the flood mask derived from aerial photography. In comparison to the original TerraSAR-X flood mask, a significant improvement could be achieved regarding its consistency with the high resolution elevation model. That means, that elevated objects inside the flood mask such as bridges and buildings or higher ground could automatically be excluded by applying the method.

\section{Discussion of results and conclusion}

In this paper it could be demonstrated that for the given situation of the Elbe case study flood extent could not be adequately retrieved for flood depth delineation from traditional medium resolution SAR sensors such as Radarsat-1. Precise high resolution SAR-data is expected to be more suitable for such detailed studies. Generally, wind, water turbulence, shallow water over agricultural fields and flooded areas covered with vegetation cause for high backscatter values in SAR data and thus often lead to a misclassification and underestimation of the flood extent. X-Band sensors such as TerraSAR-X working with short wavelengths are even more sensitive to wind and roughness on water surfaces than the widely used C-Band systems (Horritt et al., 2003).

Geometric resolution has a substantial influence on classification accuracy and flood mask derivation. However, the derivation of the flood mask was not the main focus of this study. This paper rather concentrates on methods for correcting and improving flood masks and it elaborates on how precise maps of flood depth can be derived. With regard to scale it can be stated that the accuracy of the approach presented here, highly depends on the quality and resolution of the DEM used for this analysis. Also the relation of remote sensing and elevation data regarding their geometric resolution and quality are of importance. Ideally, both datasets 
should have a spatial sampling of $3 \mathrm{~m}$ minimum, with the DEM resolution being higher than the resolution of the remote sensing data.

It can be concluded from this study, that for high resolution SAR data in combination with very high resolution elevation data the proposed methodology allows the generation of hydraulically improved maps of inundation depth. However, certain boundary conditions have to be taken into account when applying the profile method. For the adequate estimation of the water level, it is crucial to determine the accurate position of the flood water boundary. Since the water level is strongly correlated to flood extent, the terrain which confines the flood water should have a moderate slope to apply the method properly. A very steep slope would lead to increasing errors, because small changes in flood extent would lead to high variation in the water level estimates. This means that this method should only be applied for large flood events in which the normal river channel is overtopped. Apart from dense vegetation and urban structures at the flood boundary, also extremely flat terrain seems to cause problems with the accurate identification of the flood extent and thus can lead to errors in the derived water level estimates.

This study was able to demonstrate problems and possible solutions when combining two different data sets - satellite data and DEM - for flood analysis and how to overcome discrepancies which can occur during the matching process. Even if both datasets are considered as highly accurate and their spatial resolution is in good accordance, a significant inconsistency may emerge as shown by the scattering of the water level estimates in the longitudinal profile. The causes for this are manifold and errors must be considered in both datasets. These errors may also be superimposed and can not be disentangled without high quality spatial validation data from the exact time of the satellite overpass. In the absence of such validation data the two data sets have to be weighted against each other. In the proposed approach the DEM is considered as "truth" because of the very high spatial resolution and accuracy of LiDAR, although there may still be some residual errors. In order to achieve coherence between the two data sets the flood mask is manipulated and fitted onto the DEM.

The proposed methodology does not work well in urban areas in which it is difficult to detect the exact position of the flood boundary in SAR-images in these image regions. The incidence angle of SAR systems as well as shadow/layover effects and strong backscattering (double bounce) caused by urban structures can all hamper the visibility of flood water in urban areas. However, the higher resolution SpotLight mode of TerraSAR-X should be used to find out more about the potential of this sensor's ability to detect flood water in built-up areas. Assuming that the flood boundary can be reliably deduced for at least one side of the river bank in urban areas, a very precise potential flood mask can still be provided for these areas without considering levees or mobile flood barriers
The proposed method was developed in the context of the earth-observation based mapping of flood parameters in support of disaster management operations as well as to rapidly estimate flood damages. The requirements of such applications are fulfilled in a way that computation time is negligible and data requirements are low, i.e. only high resolution remote sensing data and LiDAR elevation data are needed. This work does not intend to replace accurate hydraulic modeling approaches which are more complex with respect to data requirements, parameterisation and computation time.

The proposed method has not yet been applied in realtime flood mapping operations, but is expected to improve accuracy and hydraulic reliability of SAR-based flood monitoring applications significantly. The main drawback of the profile method is that it depends on the availability of high resolution digital elevation models which are rather expensive and not readily available for a large number of basins. However, during the last years LiDAR DEMs became more and more available and have been successfully used for hydraulic applications in river flood plains. In the near future, the upcoming TanDEM-X satellite constellation renders the possibility to provide elevation data of a new dimension on a global scale (Krieger et al., 2005). On this basis the proposed methodology represents a promising tool for improving flood monitoring and flood mapping, especially in large ungauged basins.

Acknowledgements. This work was supported by the Helmholtz Association of German Research Centres and the German Aerospace Center (DLR) within the framework of the "DISFLOOD" Project. The authors wish to thank the Environment Agency of England and Wales for providing the LiDAR DEM and aerial photography of the Tewkesbury region. Special thanks go to André Twele for supporting the flood depth computations and reading the manuscript, Alexandra Förster for reading the manuscript, Sandro Martinis for providing the TerraSAR-X flood mask and Marianne Wargenau for digitising the flood mask from aerial photos. Finally, the authors wish to thank the Referees for their constructive comments which greatly improved the paper.

Edited by: N. Verhoest

\section{References}

Baatz, M. and Schäpe, A.: Multiresolution Segmentation-an optimization approach for high quality multi-scale image segmentation, Angewandte Geographische Informationsverarbeitung XII. Beiträge zum AGIT-Symposium Salzburg, 200, 12-23, 2000.

Bates, P. D., Wilson, M. D., Horritt, M. S., Mason, D. C., Holden, N., and Currie, A.: Reach scale floodplain inundation dynamics observed using airborne synthetic aperture radar imagery: Data analysis and modeling, J. Hydrol., 328, 306-318, 2006.

Blaschke, T., Lang, S., Lorup, E., Strobl, J., and Zeil, P.: Objectoriented image processing in an integrated GIS/remote sensing environment and perspectives for environmental applications, in: Environmental Information for Planning, Politics and the Pub- 
lic, edited by: Cremers, A. and Greve, K.: Metropolis Verlag, Marburg, Germany, 2, 555-570, 2000.

Bonn, F. and Dixon, R.: Monitoring Flood Extent and Forecasting Excess Runoff Risk with RADARSAT-1 Data, Nat. Hazards, 35, 377-393, 2005.

Brivio, P. A., Colombo, R., Maggi, M., and Tomasoni, R.: Integration of remote sensing data and GIS for accurate mapping of flooded areas, Int. J. Remote Sens., 23, 429-441, 2002.

Fowler, R. A.: LIDAR for Flood Mapping, Earth Observation Magazine, 9, 2002, http://www.eomonline.com/Common/Archives/ July00/robert.htm, access: 25 August, 2008.

Horritt, M. S., Mason, D. C., Cobby, D. M., Davenport, I. J., and Bates, P. D.: Waterline mapping in flooded vegetation from airborne SAR imagery, Remote Sens. Environ., 85, 271-281, 2003.

Krieger, G., Fiedler, H., Hajnsek, I., Eineder, M., Werner, M., and Moreira, A.: TanDEM-X: mission concept and performance analysis, IEEE International Geoscience and Remote Sensing Symposium Proceedings, 2005 (IGARSS '05), 25-29 July 2005, Seoul, South Korea, 4890-4893, 2005.

Ling, F., Xiao, F., Du, Y., 5 Xue, H. P., and Ren, X. Y.: Waterline mapping at the subpixel scale from remote sensing imagery with high-resolution digital elevation models, Int. J. Remote Sens., 29, 1809-1815, 2008.

Mason, D. C., Horrit, M. S., Dall'Amico, J. T., Scott, T. R., and Bates, P. D.: Improving River Flood Extent Delineation From Synthetic Aperture Radar Using Airborne Laser Altimetry, IEEE T. Geosci. Remote, 45, 3932-3943, 2007.

Matgen, P., Schumann, G., Henry, J. B., Hoffmann, L., and Pfister, L.: Integration of SAR derived river inundation areas, highprecision topographic data and a river flow model toward near real-time flood management, Int. J. Appl. Earth Obs., 9, 247263, 2007

Meinel, G., Schumacher, U., and Hennersdorf, J.: GIS-Technical Evaluation of the Flood Disaster in Summer 2002 with respect to the City of Dresden on the Basis of Remote Sensing, Laser Scanner and Measurement Data, ISPRS International Archives of the Photogrammetry, Remote Sensing and Spatial Information Sciences, XXXIV, 104-111, 2003.
Pappenberger, F., Frodsham, K., Beven, K., Romanowicz, R., and Matgen, P.: Fuzzy set approach to calibrating distributed flood inundation models using remote sensing observations, Hydrol. Earth Syst. Sci., 11, 739-752, 2007, http://www.hydrol-earth-syst-sci.net/11/739/2007/.

Sanders, B. F.: Evaluation of on-line DEMs for flood inundation modeling, Adv. Water Resour., 30, 1831-1843, 2007.

Sanyal, J. and Lu, X. X.: Application of Remote Sensing in Flood Management with Special Reference to Monsoon Asia: A Review, Nat. Hazards, 33, 283-301, 2004.

Schneiderhan, T., Huber, M., Zwenzner, H., and Hoffmann, J.: Use of ENVISAT ASAR and ERS SAR data for flood rapid mapping, ENVISAT Symposium, Montreux, Swiss, 2007.

Schumann, G., Black, A., Cutler, M., Henry, J.-B., Hoffmann, L., Matgen, P., and Pfister, L.: Hydraulic and event knowledge to reduce the positional uncertainty in SAR flood images for improved flood model calibration and development, 7th International Symposium on Spatial Accuracy Assessment in Natural Resources and Environmental Sciences., Lisbon, Portugal, 633642, 2006.

Schumann, G., Hostache, R., Puech, C., Hoffmann, L., Matgen, P., Pappenberger, F., and Pfister, L.: High-Resolution 3-D Flood Information From Radar Imagery for Flood Hazard Management, IEEE T. Geosci. Remote, 45, 1715-1725, 2007.

Sheng, Y. and Xia, Z.-G.: A comprehensive evaluation of filters for radar speckle suppression, in: Remote Sensing for a Sustainable Future, International Geoscience and Remote Sensing Symposium (IGARSS), Lincoln, Nebraska, USA, 1559-1561, 1996.

Thieken, A. H., Müller, M., Kreibich, H., and Merz, B.: Flood damage and influenceing factors: New insights from the August 2002 flood in Germany, Water Resour. Res., 41, 1-16, 2005.

Wang, Y.: Seasonal change in the extent of inundation on floodplains detected by JERS-1 Synthetic Aperture Radar data, Int. J. Remote Sens., 25, 2497-2508, 2004. 